\title{
Real Business Cycles, Animal Spirits, and Stock Market Valuation
}

\author{
Kevin J. Lansing \\ Federal Reserve Bank of San Francisco
}

August 2018

Working Paper 2018-08

https://www.frbsf.org/economic-research/publications/working-papers/2018/08/

\section{Suggested citation:}

Kevin J. Lansing. 2018. "Real Business Cycles, Animal Spirits, and Stock Market Valuation,” Federal Reserve Bank of San Francisco Working Paper 2018-08. https://doi.org/10.24148/wp2018-08

The views in this paper are solely the responsibility of the authors and should not be interpreted as reflecting the views of the Federal Reserve Bank of San Francisco or the Board of Governors of the Federal Reserve System. 


\title{
Real Business Cycles, Animal Spirits, and Stock Market Valuation*
}

\author{
Kevin J. Lansing ${ }^{\dagger}$ \\ Federal Reserve Bank of San Francisco
}

August 1, 2018

\begin{abstract}
This paper develops a real business cycle model with five types of fundamental shocks and one "equity sentiment shock" that captures animal spirits-driven fluctuations. The representative agent's perception that movements in equity value are partly driven by sentiment turns out to be close to self-fulfilling. I solve for the sequences of shock realizations that allow the model to exactly replicate the observed time paths of U.S. consumption, investment, hours worked, the stock of physical capital, capital's share of income, and the S\&P 500 market value from 1960.Q1 onwards. The model-identified sentiment shock is strongly correlated with survey-based measures of U.S. consumer sentiment. Counterfactual scenarios with the model suggest that the equity sentiment shock has an important influence on the paths of most U.S. macroeconomic variables.
\end{abstract}

Keywords: Belief-driven business cycles, Excess volatility, Animal spirits, Sentiment, Bubbles.

JEL Classification: E32, E44, O41.

\footnotetext{
*Forthcoming in International Journal of Economic Theory. This paper began as a discussant presentation prepared for the May 15, 2015 Conference on Multiple Equilibria and Financial Crisis, organized by Jess Benhabib and Roger Farmer and hosted by the Federal Reserve Bank of San Francisco. For helpful comments and suggestions, I thank an anonymous referee and participants at the 2018 Symposium of the Society for Nonlinear Dynamics and Econometrics held in Tokyo Japan and the 2018 CEGAP conference sponsored by Durham University Business School. Any opinions expressed here do not necessarily reflect the views of the Federal Reserve of Bank of San Francisco or the Board of Governors of the Federal Reserve System.

${ }^{\dagger}$ Research Department, Federal Reserve Bank of San Francisco, P.O. Box 7702, San Francisco, CA 941207702, kevin.j.lansing@sf.frb.org
} 
Nowhere does history indulge in repetitions so often or so uniformly as in Wall Street. When you read contemporary accounts of booms or panics the one thing that strikes you most forcibly is how little either stock speculation or stock speculators today differ from yesterday. The game does not change and neither does human nature.

From the thinly-disguised biography of legendary speculator Jesse Livermore, by E. Lefevére (1923, p. 180).

\section{Introduction}

Theories about the interaction of sentiment and expectations have long played a role in efforts to account for fluctuations in economic variables. Pigou (1927, p. 73) attributed fluctuations partly to "psychological causes" which lead people to make "errors of undue optimism or undue pessimism in their business forecasts." Keynes (1936, p. 156) likened the stock market to a "beauty contest" where participants devoted their efforts not to judging the underlying concept of beauty, but instead to "anticipating what average opinion expects the average opinion to be." More recently, Ackerloff and Shiller (2009, p. 1) assert: "We will never really understand important economic events unless we confront the fact that their causes are largely mental in nature."

This paper develops a real business cycle model that incorporates the flavor of the above ideas. The model has five types of fundamental shocks that influence labor productivity, labor disutility, the marginal efficiency of investment, the cost of adjusting the capital stock, and capital's share of income. To capture the Keynesian notion of "animal spirits," I allow for an "equity sentiment shock" that is unconnected to fundamentals.

The representative agent in the model makes use of a sentiment measure to construct a conditional forecast involving future equity value. Due to the self-referential nature of the model, the agent's perception that movements in equity value are partly driven by sentiment turns out to be close to self-fulfilling. The agent's subjective forecast errors are close to white noise with near-zero mean, giving no obvious signal that the sentiment-based forecast rule is misspecified.

I solve for the sequences of shock realizations that allow the model to exactly replicate the observed time paths of U.S. consumption, investment, hours worked, the stock of physical capital, capital's share of income, and the S\&P 500 market value from 1960.Q1 through 2017.Q4. I show that the model-identified sentiment shock is strongly correlated with survey-based measures of U.S. consumer sentiment. Counterfactual scenarios with the model suggest that the equity sentiment shock has an important influence on the paths of most U.S. macroeconomic variables.

There are a variety of ways in which animal spirits-type mechanisms can be incorporated into quantitative business cycle models. The original contributions of Benhabib and Farmer (1994) and Farmer and Guo (1994) exploit the indeterminacy of equilibrium (induced by increasing returns to scale in production) to introduce "sunspot shocks" that give rise to 
belief-driven fluctuations under rational expectations. ${ }^{1}$ In a series of papers, Farmer (2012, 2013, 2015) introduces animal spirits via a "belief function" that governs agent's expectations about future asset prices, which in turn, influence the level of employment. The belief function serves to pin down a unique rational expectations equilibrium in a framework that is otherwise missing a sufficient number of equilibrium conditions relative to endogenous variables.

Animal spirits can also be introduced by means of "news shocks" that contain noisy signals about future fundamentals. Agents' expectations and decisions rationally incorporate the noisy signal, but if the news later turns out to be wrong, it will appear as if the resulting fluctuations were not driven by fundamentals. ${ }^{2}$ Benhabib, Wang, and Wen (2015) show that rational sentiment-driven fluctuations can arise in a model without externalities or non-convexities if firms make decisions based on expected demand while households make decisions based on expected income. Milani $(2010,2017)$ introduces "expectation shocks" in a New Keynesian model that cause the representative agent's subjective forecasts to deviate from the forecasts implied by an adaptive learning algorithm. Angeletos, Collard, and Dellas (2018) introduce animal spirits by means of "confidence shocks" that arise from an individual household's belief that their own signal about productivity is unbiased whereas others receive biased signals. The confidence shock acts as wedge between an individual household's subjective expectation and the fully-rational expectation that would prevail under complete information and common priors. Chahrour and Ulbricht (2017) introduce "expectation wedges" that represent departures from full-information in an environment that is consistent with rational expectations of all agents. In the model developed here, the equity sentiment shock introduces a wedge between the representative agent's subjective forecast and the "fundamentals-only" forecast that would prevail under fully-rational expectations.

The shock-identification methodology used here shares some similarities with the approach taken by Farmer and Guo (1995) who use a real business cycle model to identify shocks that affect labor demand versus labor supply. The methodology is also conceptually similar to that of Chari, McGrattan, and Kehoe (2007) who develop a quantitative business cycle model with four "wedges" that relate to labor, investment, productivity, and government consumption. Along similar lines, Smets and Wouters (2007) and Justiniano, Primiceri, and Tambalotti (2010) employ quarterly data on seven U.S. macroeconomic variables to identify seven types of fundamental shocks in New Keynesian models. The model parameters are estimated using Bayesian methods, but unlike here, the authors do not consider their model's implications for equity value. As an alternative to estimation, I calibrate the model's parameters so that the steady state matches the U.S. data in 1970.Q4 - a period when U.S. macroeconomic ratios are close to their long-run means. More recently, Christiano, Motto, and Rostagno (2014) consider a fully-rational model with 10 fundamental shocks that is designed to match 12 macroeconomic

\footnotetext{
${ }^{1}$ These orginal models required very strong (and likely implausible) degrees of increasing returns to scale to generate indeterminacy. But subsequent iterations introduced various mechanisms that could substantially reduce the required degree of increasing returns for indeterminacy. See, for example, Wen (1998) and Guo and Lansing (2007).

${ }^{2}$ Chahrour and Jurado (2018) provide an overview of this literature and discuss how the effects of pure shifts in beliefs can be distinguished from changes in future fundamentals.
} 
and financial time series. One of these 10 shocks is an "equity shock" that is designed to help match fluctuations in the net worth of entrepreneurs.

\section{Model}

The framework for the analysis is a classic real business cycle model along the lines of Hansen (1985), but augmented to allow for: (1) growth in output per person, (2) adjustment costs for physical capital, and (3) various additional shocks. The representative agent's decision problem is to maximize

$$
\widehat{E}_{0} \sum_{t=0}^{\infty} \beta^{t}\left[\log \left(c_{t}\right)-D \exp \left(u_{t}\right) \frac{h_{t}^{1+\gamma}}{1+\gamma}\right],
$$

subject to the budget constraint

$$
c_{t}+i_{t}=w_{t} h_{t}+r_{t} k_{t},
$$

where $c_{t}$ is consumption, $h_{t}$ is hours worked, $i_{t}$ is investment (or saving), $w_{t}$ is the real wage per hour, $r_{t}$ is the real rental rate per unit of capital, and $k_{t}$ is the stock of physical capital, where quantities are measured in per person terms. The parameter $\beta \in(0,1)$ is the agent's subjective time discount factor. The symbol $\widehat{E}_{t}$ represents the agent's subjective expectation, conditional on information available at time $t$. Under rational expectations, $\widehat{E}_{t}$ corresponds to the mathematical expectation operator $E_{t}$ evaluated using the objective distribution of all shocks, which are assumed known to the rational agent. The disutility of labor is governed by the second term in (1), where $D>0$, and $\gamma \geq 0$. The elasticity of intertemporal substitution in labor supply is given by $1 / \gamma$. As $\gamma \rightarrow \infty$, the model reduces to one with fixed labor supply. Following Hall (1997), I allow for a shock $u_{t}$ that shifts the intratemporal trade-off between consumption and leisure. The "labor disutility shock" evolves according to the following stationary $\mathrm{AR}(1)$ process

$$
u_{t}=\rho_{u} u_{t-1}+\varepsilon_{u, t}, \quad\left|\rho_{u}\right|<1, \quad \varepsilon_{u, t} \sim N I D\left(0, \sigma_{\varepsilon, u}^{2}\right),
$$

where $\rho_{u}$ governs the shock persistence and $\varepsilon_{u, t}$ is a normally and independently distributed $(N I D)$ innovation with mean zero and variance $\sigma_{\varepsilon, u}^{2}$.

Resources devoted to investment augment the stock of physical capital $k_{t}$ according to the following law of motion

$$
\begin{aligned}
k_{t+1} & =B \exp \left(v_{t}\right) k_{t}^{1-\delta_{t}} i_{t}^{\delta_{t}}, \quad B>0, \\
v_{t} & =\rho_{v} v_{t-1}+\varepsilon_{v, t}, \quad\left|\rho_{v}\right|<1, \quad \varepsilon_{v, t} \sim N I D\left(0, \sigma_{\varepsilon, v}^{2}\right), \\
\delta_{t} & =\delta_{t-1}^{\rho_{\delta}} \bar{\delta}^{1-\rho_{\delta}} \exp \left(\varepsilon_{\delta, t}\right), \quad\left|\rho_{\delta}\right|<1, \quad \varepsilon_{\delta, t} \sim N I D\left(0, \sigma_{\varepsilon, \delta}^{2}\right),
\end{aligned}
$$

with $k_{0}, v_{0}$, and $\delta_{0}$ given. The nonlinear formulation of equation (4) reflects the presence of capital adjustment costs. ${ }^{3}$ Lansing (2012) shows that the Cobb-Douglas form of equation (4)

\footnotetext{
${ }^{3}$ Abstracting from shocks, the implicit cost of adjusting the capital stock from one period to the next could be computed as $B k_{t}\left[\left(n_{0}+n_{1}\left(i_{t} / k_{t}-\overline{i / k}\right)\right]-B k_{t}\left(i / k_{t}\right)^{\bar{\delta}}\right.$ where $n_{0}$ and $n_{1}$ are Taylor series coefficients and $\overline{i / k}$ is the steady-state investment-capital ratio.
} 
can be viewed as a log-linearized version of the nonlinear law of motion for capital employed by Jermann (1998). ${ }^{4}$ Following Cassou and Lansing (1997) and Lansing and Markiewicz (2018), I allow for a "capital law multiplier shock" $v_{t}$ that evolves as a stationary $\operatorname{AR}(1)$ process with persistence parameter $\rho_{v}$ and innovation variance $\sigma_{\varepsilon, v}^{2}$. The variable $\delta_{t}$ is a "capital law exponent shock" that represents stochastic variation in the elasticity of new capital with respect to new investment. When $\delta_{t}<1$, equation (4) implies the presence of time-varying capital adjustment costs. The logarithm of $\delta_{t}$ evolves as a stationary $\operatorname{AR}(1)$ process with persistence parameter $\rho_{\delta}$, innovation variance $\sigma_{\varepsilon, \delta}^{2}$, and steady state value $\bar{\delta}$. In addition to time-varying adjustment costs, the two capital law shocks can be viewed as capturing shifts in the marginal efficiency of investment, along the lines of Justiniano, Primiceri, and Tambalotti (2010) and/or stochastic variation in the capital depreciation rate, along the lines of Ambler and Paquet (1994), Liu, Waggoner and Zha (2011), and Furlanetto and Seneca (2014). A study by Greenwood, Hercowitz, and Huffman (1988) was the first to consider shocks to the capital law of motion as an important driving force for business cycle fluctuations. More generally, shocks that appear in the capital law of motion can be interpreted as capturing financial frictions that impact the supply of new capital and the price of claims to existing capital.

The representative agent derives income by supplying labor and capital services to identical competitive firms. Firms produce output according to the technology

$$
\begin{aligned}
y_{t} & =A k_{t}^{\alpha t}\left[\exp \left(z_{t}\right) h_{t}\right]^{1-\alpha_{t}}, \quad A>0, \\
z_{t} & =z_{t-1}+\mu+\varepsilon_{z, t}, \quad \varepsilon_{z, t} \sim \operatorname{NID}\left(0, \sigma_{\varepsilon, z}^{2}\right), \\
\alpha_{t} & =\alpha_{t-1}^{\rho_{\alpha}} \bar{\alpha}^{1-\rho_{\alpha}} \exp \left(\varepsilon_{\alpha, t}\right), \quad\left|\rho_{\alpha}\right|<1, \quad \varepsilon_{\alpha, t} \sim N I D\left(0, \sigma_{\varepsilon, \alpha}^{2}\right),
\end{aligned}
$$

with $z_{0}$ and $\alpha_{0}$ given. In equation $(7), z_{t}$ represents a "labor productivity shock" that evolves as a random walk with drift. The drift parameter $\mu>0$ determines the trend growth rate of output per person in the economy. Stochastic variation in the production function exponent $\alpha_{t}$ represents a "factor distribution shock," along the lines of Young (2004), Ríos-Rull and Santaeulàlia-Llopis (2010), Lansing (2015), and Lansing and Markiewicz (2018). The logarithm of $\alpha_{t}$ evolves as a stationary $\operatorname{AR}(1)$ process with persistence parameter $\rho_{\alpha}$, innovation variance $\sigma_{\varepsilon, \alpha}^{2}$, and steady state value $\bar{\alpha}$.

Profit maximization by firms yields the factor prices

$$
\begin{aligned}
w_{t} & =\left(1-\alpha_{t}\right) y_{t} / h_{t}, \\
r_{t} & =\alpha_{t} y_{t} / k_{t},
\end{aligned}
$$

which together imply $y_{t}=w_{t} h_{t}+r_{t} k_{t}$. From equation (11), we can see that stochastic variation in $\alpha_{t}\left(=r_{t} k_{t} / y_{t}\right)$ will allow the model to capture the observed fluctuations in the U.S. capital share of income (Figure 1).

\footnotetext{
${ }^{4}$ Specifically, $k_{t+1} / k_{t}=1-d+\psi_{0}\left(i_{t} / k_{t}\right)^{\psi_{1}} \simeq B_{0}\left[\left(i_{t} / k_{t}\right) /(\overline{i / k})\right]^{\delta}$, where $B_{0}$ and $\delta$ are Taylor series coefficients. Stochastic variation in the parameters $d, \psi_{0}$, or $\psi_{1}$ would imply stochastic variation in the coefficients $B_{0}$ and $\delta$.
} 
The first-order conditions with respect to $c_{t}, h_{t}$, and $k_{t+1}$ are given by

$$
\begin{aligned}
& \lambda_{t}=1 / c_{t}, \\
& D \exp \left(u_{t}\right) h_{t}^{\gamma}=\lambda_{t} w_{t} \\
& \lambda_{t} i_{t} /\left(\delta_{t} k_{t+1}\right)=\beta \widehat{E}_{t} \lambda_{t+1}\left[r_{t+1}+\left(1-\delta_{t+1}\right) i_{t+1} /\left(\delta_{t+1} k_{t+1}\right)\right]
\end{aligned}
$$

where $\lambda_{t}$ is the Lagrange multiplier on the budget constraint (2). From equation (13), we see that an increase in $\exp \left(u_{t}\right)$ is isomorphic to a higher distortionary tax on labor income. In deriving equation (14), I first use the capital law of motion (4) to eliminate $i_{t}$ from the budget constraint. Since $k_{t+1}$ is known at time $t$, equation (14) can be rewritten as follows

$$
\underbrace{i_{t} / \delta_{t}}_{p_{t}}=\widehat{E}_{t}\left\{M_{t+1}[\underbrace{\alpha_{t+1} y_{t+1}-i_{t+1}}_{d_{t+1}}+\underbrace{i_{t+1} / \delta_{t+1}}_{p_{t+1}}]\right\},
$$

where $M_{t+1} \equiv \beta\left(c_{t+1} / c_{t}\right)^{-1}$ is the stochastic discount factor. The rewritten first-order condition (15) is now in the form of a standard asset pricing equation where $p_{t}=i_{t} / \delta_{t}$ represents the market value of the agent's equity shares in the firm. The equity shares entitle the agent to a perpetual stream of dividends $d_{t+1}$ starting in period $t+1$. As originally noted by Basu (1987), the functional form of the capital law of motion (4) implies a direct link between the market value of equity and firms' investment in physical capital. This feature of the model is consistent with the observed low-frequency comovement between the real S\&P 500 stock market index and real business investment in recent decades, as documented by Lansing (2012).

\subsection{Fundamental equity value}

Defining the equity value-consumption ratio (a stationary variable) as $x_{t} \equiv p_{t} / c_{t}=i_{t} /\left(\delta_{t} c_{t}\right)$, the first order condition (15) becomes

$$
\begin{aligned}
x_{t} & =\beta \widehat{E}_{t}\left\{\alpha_{t+1} y_{t+1} / c_{t+1}+\left(1-\delta_{t+1}\right) x_{t+1}\right\} \\
& =\beta \widehat{E}_{t} \underbrace{\left\{\alpha_{t+1}+\left[1-\delta_{t+1}\left(1-\alpha_{t+1}\right)\right] x_{t+1}\right\}}_{\equiv q_{t+1}},
\end{aligned}
$$

where I have used the budget constraint (2) at time $t+1$ and the definition of $x_{t+1}$ to make the substitution $y_{t+1} / c_{t+1}=1+\delta_{t+1} x_{t+1}$. At this point, it is convenient to define a nonlinear change of variables such that $q_{t+1}$ represents the composite stationary variable that the agent must forecast. ${ }^{5}$ The agent's first-order condition (16) becomes $x_{t}=\beta \widehat{E}_{t} q_{t+1}$. Now using the definition of $q_{t}$ to make the substitution $x_{t}=\left(q_{t}-\alpha_{t}\right) /\left[1-\delta_{t}\left(1-\alpha_{t}\right)\right]$ yields the following transformed version of the agent's first order condition

$$
q_{t}=\alpha_{t}+\beta\left[1-\delta_{t}\left(1-\alpha_{t}\right)\right] \widehat{E}_{t} q_{t+1} .
$$

\footnotetext{
${ }^{5}$ This nonlinear change of variables technique is also employed by Lansing $(2010,2016)$.
} 
The fundamental equity value is obtained by solving equation (17) under the assumption of rational expectations such that $\widehat{E}_{t} q_{t+1}=E_{t} q_{t+1}$. As shown in Appendix A, a log-linear approximate version of the fundamental solution is given by

$$
q_{t}^{\mathrm{f}}=\bar{q}^{\mathrm{f}}\left[\frac{\alpha_{t}}{\bar{\alpha}}\right]^{\gamma_{\alpha}}\left[\frac{\delta_{t}}{\bar{\delta}}\right]^{\gamma_{\delta}}
$$

where $\bar{q}^{\mathrm{f}} \equiv \exp \left[E \log \left(q_{t}^{\mathrm{f}}\right)\right]$ and $\gamma_{\alpha}$ and $\gamma_{\delta}$ are solution coefficients that depend on model parameters. Given the value of $q_{t}^{\mathrm{f}}$, we can recover the fundamental equity value-consumption ratio as

$$
x_{t}^{\mathrm{f}} \equiv \frac{p_{t}^{\mathrm{f}}}{c_{t}}=\frac{q_{t}^{\mathrm{f}}-\alpha_{t}}{1-\delta_{t}\left(1-\alpha_{t}\right)},
$$

which shows that $p_{t}^{\mathrm{f}} / c_{t}$ will only move in response to the two fundamental shocks $\alpha_{t}$ and $\delta_{t}$.

\section{$2.2 \quad$ Introducing animal spirits}

Numerous empirical studies starting with Shiller (1981) and LeRoy and Porter (1981) have shown that stock prices appear to exhibit excess volatility when compared to fundamentals, as measured by the discounted stream of ex post realized dividends. ${ }^{6}$ To capture the notion of animal spirits-driven excess volatility, I allow for an "equity sentiment shock" that is unconnected to fundamentals. I postulate that the representative agent's perceived law of motion (PLM) for the composite variable $q_{t}$ in equation (17) takes into account the possibility of departures from the fundamental value $q_{t}^{\mathrm{f}}$. Specifically, the agent's PLM takes the form

$$
\begin{aligned}
& q_{t}=q_{t}^{\mathrm{f}} \exp \left(s_{t}\right), \\
& s_{t}=\rho_{s} s_{t-1}+\varepsilon_{s, t}, \quad\left|\rho_{s}\right|<1, \quad \varepsilon_{s, t} \sim N I D\left(0, \sigma_{\varepsilon, s}^{2}\right),
\end{aligned}
$$

where the sentiment shock $s_{t}$ evolves as a stationary $\mathrm{AR}(1)$ process with persistence parameter $\rho_{s}$, innovation variance $\sigma_{\varepsilon, s}^{2}$, and a steady state value of zero. The agent can learn the parameters that govern the sentiment shock by constructing the time series $\log \left(q_{t} / q_{t}^{\mathrm{f}}\right)$ where $q_{t}$ is the actual value observed in the data and $q_{t}^{\mathrm{f}}$ is the value predicted by fundamentals from equation (18).

Given the PLM (20), the agent's subjective forecast can be computed as follows

$$
\begin{aligned}
\widehat{E}_{t} q_{t+1} & =\widehat{E}_{t} q_{t+1}^{\mathrm{f}} \exp \left(\rho_{s} s_{t}+\frac{1}{2} \sigma_{\varepsilon, s}^{2}\right) \\
& =\bar{q}^{\mathrm{f}} \exp \left(\frac{1}{2} \gamma_{\alpha}^{2} \sigma_{\varepsilon, \alpha}^{2}+\frac{1}{2} \gamma_{\delta}^{2} \sigma_{\varepsilon, \delta}^{2}+\frac{1}{2} \sigma_{\varepsilon, s}^{2}\right)\left[\frac{\alpha_{t}}{\bar{\alpha}}\right]^{\rho_{\alpha} \gamma_{\alpha}}\left[\frac{\delta_{t}}{\bar{\delta}}\right]^{\rho_{\delta} \gamma_{\delta}} \exp \left(\rho_{s} s_{t}\right),
\end{aligned}
$$

where $\widehat{E}_{t} q_{t+1}^{\mathrm{f}}\left(=E_{t} q_{t+1}^{\mathrm{f}}\right)$ is the "fundamentals-only" forecast that ignores the sentiment shock. Equation (22) is qualitatively consistent with the findings of Frydman and Stillwagon (2018). Using survey data of investors' expectations about future stock returns, they present evidence that expectations are jointly driven by fundamental factors and extrapolation. Substituting

\footnotetext{
${ }^{6}$ Lansing and LeRoy (2014) provide a recent update on this literature.
} 
the agent's subjective forecast (22) into the first order condition (17) yields the actual law of motion (ALM) for $q_{t}$. Due to the self-referential nature of the model whereby $q_{t}$ depends in part on $\widehat{E}_{t} q_{t+1}$, the resulting ALM for $q_{t}$ does indeed depend on $s_{t}$, making the agent's beliefs close to self-fulfilling. Given the ALM for $q_{t}$, we can we can recover the resulting equity value-consumption ratio as

$$
x_{t} \equiv \frac{p_{t}}{c_{t}}=\frac{q_{t}-\alpha_{t}}{1-\delta_{t}\left(1-\alpha_{t}\right)}=\beta \widehat{E}_{t} q_{t+1}
$$

where $q_{t}=q\left(\alpha_{t}, \delta_{t}, s_{t}\right)$. Hence, $p_{t} / c_{t}$ will move in response to movements in $\alpha_{t}, \delta_{t}$, or $s_{t}$.

Given the value of $x_{t}$ from equation (23), we can compute the values of the other macroeconomic variables using the following equations

$$
\begin{aligned}
h_{t} & =\left[\left(1-\alpha_{t}\right)\left(1+\delta_{t} x_{t}\right) D^{-1} \exp \left(-u_{t}\right)\right]^{\frac{1}{1+\gamma}} \\
y_{t} & =A k_{t}^{\alpha_{t}}\left[\exp \left(z_{t}\right) h_{t}\right]^{1-\alpha_{t}} \\
c_{t} & =y_{t} /\left(1+\delta_{t} x_{t}\right) \\
i_{t} & =y_{t} \delta_{t} x_{t} /\left(1+\delta_{t} x_{t}\right)
\end{aligned}
$$

where I have used the budget relationship $y_{t} / c_{t}=1+\delta_{t} x_{t}$.

\section{Parameter values and shocks}

Figure 1 plots the U.S. data versions of the model variables $y_{t}, c_{t}, i_{t}, h_{t}, k_{t}, p_{t}$, and $\alpha_{t}$. Figure 2 plots the U.S. data versions of the model ratios $c_{t} / y_{t}, i_{t} / y_{t}, k_{t} / y_{t}$, and $p_{t} / y_{t}{ }^{7}$ From Figure 2, we see that the U.S. macroeconomic ratios are all close to their long-run means in 1970.Q4. I choose parameters so that the steady-state, trend, or ergodic mean values of the model variables correspond to the values observed in the data in 1970.Q4. ${ }^{8}$ Given a time endowment normalized to one, a steady state target of $h_{t}=0.3$ implies that the representative agent spends about one-third of available time in market work. Table 1 summarizes the parameter values.

Table 1: Model Parameter Values

\begin{tabular}{ccl}
\hline \hline Parameter & Value & \multicolumn{1}{c}{ Description/Target } \\
\hline $\bar{\alpha}$ & 0.3507 & $\alpha_{t}=\bar{\alpha}$ in 1970.Q4. \\
$A$ & 0.9662 & $z_{t}=0$ and $k_{t} / y_{t}=10.248$ in 1970.Q4. \\
$\bar{\delta}$ & 0.0639 & $\delta_{t}=\bar{\delta}$ and $i_{t} / y_{t}=0.2690$ in 1970.Q4. \\
$B$ & 1.2894 & $v_{t}=0$ and $k_{t+1} / k_{t}=B\left(i_{t} / k_{t}\right)^{\delta}=1.0219$ in 1970.Q4. \\
$D$ & 2.9610 & $u_{t}=0$ and $h_{t}=0.3$ in 1970.Q4. \\
$\beta$ & 0.9801 & $s_{t}=0$ and $p_{t} / y_{t}=4.2112$ in 1970.Q4. \\
$\gamma$ & 0 & Indivisible labor: Rogerson (1988), Hansen (1985). \\
\hline
\end{tabular}

\footnotetext{
${ }^{7}$ The sources and methods used to construct the U.S. data versions of the model variables are described in Appendix B.

${ }^{8}$ As shown in Appendix A, the ergodic mean value of $\bar{q}^{\mathrm{f}} \equiv \exp \left[E \log \left(q_{t}^{\mathrm{f}}\right)\right]$ depends on the shock variances $\sigma_{\varepsilon, \delta}^{2}$ and $\sigma_{\varepsilon, \alpha}^{2}$. Given the shock variances, the value of the discount factor $\beta$ is chosen such that $\bar{q}^{\mathrm{f}}=q_{t}$ in 1970 .Q4
} 
Given the parameter values in Table 1, I solve for the sequences of stochastic shocks that allow the calibrated model to exactly replicate the observed time paths of the seven U.S. macro variables plotted in Figure 1. Of the seven variables, only six are independent since $y_{t}=c_{t}+$ $i_{t}$. The model has six independent shocks, so each shock series is uniquely identified. ${ }^{9}$ The model shocks are: $z_{t}$ (labor productivity), $u_{t}$ (labor disutility), $v_{t}$ (capital law multiplier), $\delta_{t}$ (capital law exponent), $\alpha_{t}$ (factor distribution), and $s_{t}$ (equity sentiment). The time series for $\alpha_{t}$ is directly pinned down by U.S. data on capital's share of income. The times series for the remaining five shocks are computed using the following equations:

$$
\begin{aligned}
z_{t} & =\left[\log \left(y_{t}\right)-\log \left(A k_{t}^{\alpha_{t}} h_{t}^{1-\alpha_{t}}\right)\right] /\left(1-\alpha_{t}\right), \\
\delta_{t} & =\left(i_{t} / y_{t}\right) /\left[\left(p_{t} / c_{t}\right)\left(1-i_{t} / y_{t}\right)\right] \\
v_{t} & =\log \left(k_{t+1} / k_{t}\right)-\log (B)-\delta_{t} \log \left(i_{t} / k_{t}\right), \\
u_{t} & =\log \left\{\left(1-\alpha_{t}\right)\left(c_{t} / y_{t}\right)^{-1} /\left(D h_{t}^{1+\gamma}\right)\right\} \\
s_{t} & =\left(1 / \rho_{s}\right) \log \left\{\left(p_{t} / c_{t}\right)\left(\beta \widehat{E}_{t} q_{t+1}^{\mathrm{f}}\right)^{-1} \exp \left(-\frac{1}{2} \sigma_{\varepsilon, s}^{2}\right)\right\}
\end{aligned}
$$

where the right-side macroeconomic variables take on the values observed in the U.S. data from 1960.Q1 to 2017.Q4. ${ }^{10}$ If a shock appears on the right side, then it takes on the value identified in a previous equation. In the case of equation (32), the fundamentals-only forecast $\widehat{E}_{t} q_{t+1}^{\mathrm{f}}\left(=E_{t} q_{t+1}^{\mathrm{f}}\right)$ is computed using the fundamental solution (18). The parameters $\beta, \rho_{s}$ and $\sigma_{\varepsilon, s}$ influence computed time series for $s_{t}$. I start with initial guesses for these parameters and then iterate until convergence.

The six identified shock series are plotted in Figure 3. By construction, all shocks are equal to their trend or steady state values in 1970.Q4. ${ }^{11}$ The labor productivity shock $z_{t}$ drops sharply in the aftermath of the Great Recession and has yet to fully recover. The labor disutility shock $u_{t}$ trends down over time, allowing the model to match the observed time path of $h_{t}$ in the data, despite the sustained weakness in labor productivity (and the real wage) together with the decline in labor's share of income implied by the increase in $\alpha_{t} .{ }^{12}$ The capital law multiplier shock $v_{t}$ is almost perfectly negatively correlated with the quantity $1-\delta_{t}$, representing the exponent on $k_{t}$ in the capital law of motion (4). This offsetting pattern allows the model to match the smooth time path of $k_{t}$ in the data while simultaneously matching the more-volatile time paths of $i_{t}$ and $p_{t}$. Finally, the equity sentiment shock $s_{t}$ mimics movements the U.S. valuation ratio $p_{t} / y_{t}$ shown earlier in Figure 2. The sentiment shock reaches its maximum value in 2000.Q1, coinciding with the peak of the NASDAQ technology stock bubble. Empirical valuation models similarly imply that U.S. equity values were above levels that can be justified by fundamentals around this time (Lansing 2017). The sentiment

\footnotetext{
${ }^{9}$ Lansing and Markiewicz (2018) and Gelain, Lansing, and Natvik (2018) undertake similar shock identification excercises, but in the context of different models.

${ }^{10}$ Since the computation of $v_{t}$ requires data at time $t+1$, I set the end-of-sample shock value to $v_{T}=\rho_{v} v_{T-1}$.

${ }^{11}$ The trend value of $z_{t}$ is constructed as $\bar{z}_{t}=\bar{z}_{t-1}+\mu$, where $\mu$ is the sample mean of $\Delta z_{t}$ and $\bar{z}_{t}=z_{t}$ in 1970.Q4.

${ }^{12}$ Kaplan and Schulhofer-Wohl (2018) show that labor disutility, as measured by "feelings about work" from surveys, has shifted in significant ways since 1950.
} 
shock is negative from 1973.Q4 through 1997.Q1 and from 2002.Q2 through 2017.Q4. These two intervals include five out of the eight U.S. recessions that have occurred since 1960.

Table 2 shows the values of the shock parameters implied by the identification exercise. The five stationary shocks all exhibit very strong persistence - close to a unit root. In this way, variables which are presumed stationary in the model (e.g., hours worked per person, capital's share of income, and the equity value-consumption ratio) can be made to replicate the sustained uptrends or downtrends observed in the U.S. data.

Table 2: Model-Identified Shock Parameters

\begin{tabular}{lcc}
\hline \hline \multicolumn{1}{c}{ Shock } & \multicolumn{2}{c}{ Values } \\
\hline Labor productivity, $z_{t}$ & $\mu=0.0046$ & $\sigma_{\varepsilon, z}=0.0301$ \\
Labor disutility, $u_{t}$ & $\rho_{u}=0.9945$ & $\sigma_{\varepsilon, u}=0.0099$ \\
Capital law multiplier, $v_{t}$ & $\rho_{v}=0.9732$ & $\sigma_{\varepsilon, v}=0.0273$ \\
Capital law exponent, $\delta_{t}$ & $\rho_{\delta}=0.9789$ & $\sigma_{\varepsilon, \delta}=0.0820$ \\
Factor distribution, $\alpha_{t}$ & $\rho_{\alpha}=0.9796$ & $\sigma_{\varepsilon, \alpha}=0.0130$ \\
Equity sentiment, $s_{t}$ & $\rho_{s}=0.9760$ & $\sigma_{\varepsilon, s}=0.0423$ \\
\hline
\end{tabular}

\section{Quantitative Analysis}

\subsection{Model-identified sentiment shock}

Movements in the equity sentiment shock capture the notion of animal spirits-driven fluctuations. Figure 4 plots impulse response functions for a one standard deviation innovation of the equity sentiment shock. The panels show the percent deviation of each variable from its no-shock trend. On impact, output, hours worked, investment, and equity value all increase. But since the capital stock cannot respond immediately, the initial increase in output is not sufficient to allow both consumption and investment to increase on impact. Consumption drops slightly on impact, but then increases with the other variables as the capital stock starts increasing in response to higher investment. Since $\delta_{t}$ is constant here, movements in equity value $\left(p_{t}=i_{t} / \delta_{t}\right)$ exactly mimic the movements in investment.

Figure 5 provides a check on the reasonableness of the model sentiment shock. The identified series for $s_{t}$ is plotted together with the University of Michigan's consumer sentiment index and the Conference Board's consumer confidence index. Each series is demeaned and normalized by its standard deviation. The model equity sentiment shock is strongly correlated with both of the survey-based measures of U.S. consumer sentiment. The correlation coefficient between $s_{t}$ and the University of Michigan index is 0.63 . The correlation coefficient between $s_{t}$ and the Conference Board index is 0.71. The strong correlation is perhaps not surprising because the identified series for $s_{t}$ helps the model to exactly replicate the time path of U.S. equity value. There is a well-documented link between equity price (or equity return) movements in the data and measures of investor or consumer sentiment. ${ }^{13}$ Still, Figure 5 confirms that it is appropriate to view the model-identified series for $s_{t}$ as capturing a

\footnotetext{
${ }^{13}$ See, for example, Fisher and Statman (2003), Brown and Cliff (2004, 2005), Schmeling (2009), Greenwood and Shleifer (2014), Frydman and Stillwagon (2018), and Lansing, LeRoy, and Ma (2018).
} 
measure of sentiment.

\subsection{Representative agent's forecast errors}

Recall from Section 2.2 that the equity sentiment shock introduces a wedge between the agent's subjective forecast $\widehat{E}_{t} q_{t+1}$ and the "fundamentals-only" forecast that ignores the sentiment shock. Table 3 summarizes the properties of the agent's percentage forecast errors, measured as $\operatorname{err}_{t+1}=100\left(q_{t+1}-\widehat{E}_{t} q_{t+1}\right) / q_{t+1}$. The forecast errors are computed for the sample period 1960.Q2 to 2017.Q4 using the model together with the six identified shock series shown in Figure 3. The agent's perception that movements in $q_{t}$ are partly driven by movements in $s_{t}$ turns out to be close to self-fulfilling. Table 3 shows that the agent's subjective forecast errors are close to white noise with near-zero mean, giving no obvious signal that the agent's sentiment-based forecast rule (22) is misspecified. In contrast, the fundamentals-only forecast performs very poorly when the ALM is given by $q_{t}=q\left(\alpha_{t}, \delta_{t}, s_{t}\right)$. Put another way, the typical agent's use of the sentiment-based forecast rule serves to shift the moments of the forecast variable $q_{t+1}$ so that any individual agent would perceive no accuracy gain from switching to the fundamentals-only forecast. ${ }^{14}$ The first-order condition (16) can also be written as $x_{t}=\beta \widehat{E}_{t} q_{t+1}$, where $x_{t} \equiv p_{t} / c_{t}$. Consequently, very similar results are obtained if the agent's percentage forecast errors are instead measured as $\operatorname{err}_{t+1}=100\left(x_{t+1}-\widehat{E}_{t} x_{t+1}\right) / x_{t+1}$.

Table 3. Properties of Representative Agent's Forecast Errors

\begin{tabular}{lcc}
\hline \hline \multicolumn{1}{c}{ Statistic } & Subjective forecast & Fundamentals-only forecast \\
\hline$E\left(\operatorname{err}_{t+1}\right)$ & $0.63 \%$ & $-15.9 \%$ \\
$\sqrt{E\left[\left(\operatorname{err}_{t+1}\right)^{2}\right]}$ & $0.84 \%$ & $2.62 \%$ \\
$\operatorname{Corr}\left(\operatorname{err}_{t+1}, \operatorname{err}_{t}\right)$ & 0.12 & 0.87 \\
$\operatorname{Corr}\left(\operatorname{err}_{t+1}, \operatorname{err}_{t-1}\right)$ & -0.02 & 0.83 \\
$\operatorname{Corr}\left(\operatorname{err}_{t+1}, \operatorname{err}_{t-2}\right)$ & 0.02 & 0.81 \\
\hline
\end{tabular}

Note: Forecast errors are computed for the sample period 1960.Q2 to 2017.Q4 using the model together with the six identified shock series shown in Figure 3.

\subsection{Counterfactual scenarios}

Figure 6 displays counterfactual scenarios for three model variables: $y_{t}, h_{t}$, and $p_{t}$. In each set of panels from top to bottom, I turn off one or more shocks (as indicated) while leaving the other shocks in place. The purpose of the exercise is see which shocks are the most important for allowing a given model variable to fit the data. A large gap between the counterfactual path and the U.S. data path (solid blue line) implies that the omitted shock(s) play an important role in allowing the model variable to match the path of the corresponding U.S. variable.

In the top set of panels, I shut off the labor productivity shock innovation $\varepsilon_{z, t}$ (dashed red lines) and then shutoff the labor disutility shock $u_{t}$ (dotted green lines). The labor productivity shock serves to hold down the levels of $y_{t}$ and $p_{t}$, particularly near the end of the data sample. But this shock has no impact on $h_{t}$ because it operates only through the ratio $c_{t} / y_{t}$, which is

\footnotetext{
${ }^{14}$ Lansing (2006) obtains a similar result in a asset pricing model where the typical agent employs extrapolative expectations.
} 
neutral to such a shock in the case of logarithmic utility. The labor disutility shock serves to push up $y_{t}$ and $h_{t}$ by a significant amount, while also pushing up $p_{t}$ in a more modest way.

In the middle set of panels, I shut off the two capital law of motion shocks $v_{t}$ and $\delta_{t}$ (dashed red lines) and then shutoff the factor distribution shock $\alpha_{t}$ (dotted green lines). The two capital law shocks serve to hold down the end-of-sample level of $y_{t}$, but have only small effects on the end-of-sample levels of $h_{t}$ and $p_{t}$. The factor distribution shock serves to push up the levels $y_{t}$ and $p_{t}$, particularly near the end of the data sample when $\alpha_{t}$ is rising more rapidly. As expected, the net effect of a rising capital income share is to push down the level of $h_{t}$. The model implication that movements in $\alpha_{t}$ can have an important impact on the level of $p_{t}$ is consistent with a recent empirical study by Greenwald, Lettau, and Ludvigson (2014) who find that highly persistent "factor share shocks" are an important driver of U.S. stock prices over the period 1952 to $2012 .^{15}$

In the bottom set of panels, I shut off the equity sentiment shock $s_{t}$ (dashed red lines) and then show the paths implied by a deterministic version of the model (dotted green lines). By itself, the equity sentiment shock serves to mostly hold down the levels of $y_{t}, h_{t}$, and $p_{t}$, except around the year 2000, coinciding with the peak of the NASDAQ technology stock bubble.

To quantify the relative importance of the various shocks for each macro variable, I compute the mean absolute gaps (measured in percent) between the counterfactual path and the U.S. data path. The results are shown in Table 3. By this metric, the labor disutility shock is the most important shock for $h_{t}$. The capital law of motion shocks are most important shocks for $c_{t}$ and $k_{t}$. The equity sentiment shock is the most important shock for $y_{t}, i_{t}$, and $p_{t}$. The last column shows the average of the mean absolute gaps across the six macroeconomic variables. By this metric, the equity sentiment shock has the strongest overall influence on the paths of the six macroeconomic variables. This result is remarkably similar to the findings of Angeletos, Collard, and Dellas (2018) who state "the confidence shock emerges as the main driver of the business cycle within medium-scale DSGE models that contain multiple other shocks."

Table 3: Mean Absolute Gaps: Model versus Data

\begin{tabular}{lccccccc}
\hline \hline Scenario & $y_{t}$ & $c_{t}$ & $i_{t}$ & $h_{t}$ & $k_{t}$ & $p_{t}$ & Ave. \\
\hline Baseline simulation & 0 & 0 & 0 & 0 & 0 & 0 & 0 \\
No labor productivity shock & 9.88 & 9.88 & 9.88 & 0 & 6.30 & 9.88 & 7.63 \\
No labor disutility shock & 11.7 & 11.7 & 11.7 & 12.4 & 10.7 & 11.7 & 11.7 \\
No capital law shocks & 12.2 & 13.7 & 19.8 & 4.31 & 37.7 & 28.5 & 19.4 \\
No factor distribution shock & 13.46 & 11.9 & 17.8 & 2.76 & 15.0 & 17.8 & 13.1 \\
No equity sentiment shock & 13.48 & 7.58 & 31.2 & 6.28 & 28.4 & 31.2 & 19.7 \\
Neterministic model & 10.9 & 12.0 & 9.96 & 9.60 & 26.8 & 40.6 & 18.3 \\
\hline
\end{tabular}

Notes: Each number is the mean absolute gap (measured in percent) between the path of the model variable under a given scenario and the path of the corresponding variable in U.S. data from 1960.Q1 to 2017.Q4. Boxed entries indicate the largest percentage gaps for each variable when other shocks are present.

\footnotetext{
${ }^{15}$ Lansing (2015) shows that the introduction of "distribution shocks" can substantially magnify the mean equity premium in a production economy with capital owners and workers.
} 


\section{Conclusion}

The main contribution of this paper is to show that an "equity sentiment shock" can be an important element in allowing a standard real business cycle model to exactly replicate the evolution of U.S. macroeconomic variables and the S\&P 500 market value from 1960.Q1 through 2017.Q4. The model-identified sentiment shock is highly correlated with survey-based measures of U.S. consumer sentiment, validating its interpretation as a type of "animal spirits," along the lines envisioned by Pigou (1927) and Keynes (1936).

In the model, the representative agent makes use of a sentiment measure to construct a conditional forecast involving future equity value. Due to the self-referential nature of the model, the agent's belief that movements in equity value are partly driven by sentiment turns out to be close to self-fulfilling. From the perspective of an individual agent, switching to a fundamentals-only forecast would appear to reduce forecast accuracy, so there is no incentive to switch. 


\section{A Appendix: Fundamental solution}

This appendix provides the details regarding the fundamental solution $q_{t}^{\mathrm{f}}$ shown in equation (18). First imposing rational expectations and then log linearizing the right-side of the transformed first order condition (17) yields

$$
q_{t}^{\mathrm{f}}=\mathrm{b}_{0}\left[\frac{\alpha_{t}}{\bar{\alpha}}\right]^{\mathrm{b}_{1}}\left[\frac{\delta_{t}}{\bar{\delta}}\right]^{\mathrm{b}_{2}} E_{t}\left[\frac{q_{t+1}^{\mathrm{f}}}{\bar{q}^{\mathrm{f}}}\right]^{\mathrm{b}_{3}},
$$

where $b_{0}, b_{1}, b_{2}$, and $b_{3}$ are Taylor-series coefficients. The expressions for the Taylor-series coefficients are

$$
\begin{aligned}
\mathrm{b}_{0} & =\bar{\alpha}+\beta[1-\bar{\delta}(1-\bar{\alpha})] \bar{q}^{\mathrm{f}}, \\
\mathrm{b}_{1} & =\frac{\bar{\alpha}\left(1+\beta \bar{\delta} \bar{q}^{\mathrm{f}}\right)}{\bar{\alpha}+\beta[1-\bar{\delta}(1-\bar{\alpha})] \bar{q}^{\mathrm{f}}}, \\
\mathrm{b}_{2}= & \frac{-\beta \bar{\delta}(1-\bar{\alpha}) \bar{q}^{\mathrm{f}}}{\bar{\alpha}+\beta[1-\bar{\delta}(1-\bar{\alpha})] \bar{q}^{\mathrm{f}}}, \\
\mathrm{b}_{3}= & \frac{\beta[1-\bar{\delta}(1-\bar{\alpha})] \bar{q}^{\mathrm{f}}}{\bar{\alpha}+\beta[1-\bar{\delta}(1-\bar{\alpha})] \bar{q}^{\mathrm{f}}}
\end{aligned}
$$

where the approximation points are $\bar{\alpha}=\exp \left[E \log \left(\alpha_{t}\right)\right], \bar{\delta}=\exp \left[E \log \left(\delta_{t}\right)\right]$ and $\bar{q}^{\mathrm{f}} \equiv$ $\exp \left[E \log \left(q_{t}^{\mathrm{f}}\right)\right]$.

A conjecture for the fundamental solution takes the form $q_{t}^{\mathrm{f}}=\bar{q}^{\mathrm{f}}\left[\alpha_{t} / \bar{\alpha}\right]^{\gamma_{\alpha}}\left[\delta_{t} / \bar{\delta}\right]^{\gamma_{\delta}}$. The conjectured solution is iterated ahead one period and then substituted into the right-side of equation (A.1) together with the laws of motion for $\alpha_{t+1}$ and $\delta_{t+1}$ from equations (9) and (6), respectively. After evaluating the conditional expectation and then collecting terms, we have

$$
q_{t}^{\mathrm{f}}=\underbrace{\mathrm{b}_{0} \exp \left[\frac{1}{2}\left(\gamma_{\alpha} \mathrm{b}_{3}\right)^{2} \sigma_{\varepsilon, \alpha}^{2}+\frac{1}{2}\left(\gamma_{\delta} \mathrm{b}_{3}\right)^{2} \sigma_{\varepsilon, \delta}^{2}\right]}_{=\bar{q}^{\mathrm{f}}} \times\left[\frac{\alpha_{t}}{\bar{\alpha}}\right] \underbrace{\mathrm{b}_{1}+\rho_{\alpha} \gamma_{\alpha} \mathrm{b}_{3}}_{\gamma_{\alpha}} \times[\frac{\delta_{t}}{\bar{\delta}} \underbrace{\mathrm{b}_{2}+\rho_{\delta} \gamma_{\delta} \mathrm{b}_{3}}_{=\gamma_{\delta}}
$$

which yields three equations in the three unknown solution coefficients $\bar{q}^{\mathrm{f}}$, and $\gamma_{\alpha}$ and $\gamma_{\delta}$. For the baseline calibration, we have $\bar{q}^{\mathrm{f}}=5.868, \gamma_{\alpha}=1.034$ and $\gamma_{\delta}=-0.499$. An increase in capital's share of income $\alpha_{t}$ will cause $q_{t}^{\mathrm{f}}$ to increase. An increase in the capital law of motion exponent $\delta_{t}$ will cause $q_{t}^{\mathrm{f}}$ to decrease. It can be shown that for the baseline calibration, the fundamental equity value-consumption ratio $x_{t}^{\mathrm{f}} \equiv p_{t}^{\mathrm{f}} / c_{t}$ computed from equation (19) will move in the same direction as $q_{t}^{\mathrm{f}}$.

\section{B Appendix: Data sources and methods}

I start with data on nominal personal consumption expenditures on nondurable goods plus services $\left(C_{t}\right)$, nominal private nonresidential fixed investment plus nominal personal consumption expenditures on durable goods $\left(I_{t}\right)$, the corresponding price indices for each of the various 
nominal expenditure series that sum to $C_{t}$ and $I_{t}$, and U.S. population. All of this data are from the Federal Reserve Bank of St. Louis' FRED database. I define the nominal ratios $C_{t} / Y_{t}$ and $I_{t} / Y_{t}$, where $Y_{t} \equiv C_{t}+I_{t}$. The nominal ratios capture shifts in relative prices. I then deflate $Y_{t}$ by an output price index constructed as the weighted-average of the price indices for the various nominal expenditure series that sum to $C_{t}$ and $I_{t}$, where the weights are the nominal expenditure ratios relative to $Y_{t}$. The level of real output per person $y_{t}$ in the data is normalized to 1.0 in 1970.Q4. The real per person series $c_{t}$ and $i_{t}$ are constructed by applying the nominal ratios $C_{t} / Y_{t}$ and $I_{t} / Y_{t}$ to the deflated output series and then dividing by U.S. population. In this way, the real per person series reflect the same resource allocation ratios as the nominal per person series.

Data for $h_{t}$ are hours worked of all persons in the nonfarm business sector from FRED, divided by U.S. population and then normalized to equal 0.3 in 1970.Q4.

The data for $k_{t}$ are constructed using the historical-cost net stock of private nonresidential fixed assets plus the historical-cost net stock of consumer durable goods, both in billions of dollars at year end, from the Bureau of Economic Analysis (BEA), NIPA Table 4.3, line 1 and Table 8.3, line 1, respectively. The data are only available at annual frequency, so I first create a quarterly series by log-linear interpolation. The nominal capital stock series is deflated using the output price index mentioned above and then divided by U.S. population. I normalize the real per person series for $k_{t}$ to deliver a target value of $i_{t} / k_{t}=0.0263$ in 1970.Q4. The target value is arbitrary given that the model parameters $B$ and $\bar{\delta}$ can be adjusted to hit any desired target value. I choose the target value of $i_{t} / k_{t}$ to coincide with the steady state value implied by a model with no capital adjustment costs, such that $i_{t} / k_{t}=k_{t+1} / k_{t}-1+d$, where $d=0.02$ is a typical quarterly depreciation rate for physical capital. For the normalization, I employ the mean quarterly growth rate of the real per person series which implies $k_{t+1} / k_{t}=\exp (0.0062)$ in steady state. I calibrate the value of $A$ in the production function (7) to yield $y_{t}=1$ in 1970.Q4 when $k_{t}$ is equal to the normalized capital stock in 1970.Q4. This procedure delivers a sample mean of $k_{t} / y_{t}=9.80$ from 1960.Q1 to 2017.Q4.

Following Lansing (2015) and Lansing and Markiewicz (2018), capital's share of income is measured as 1 minus the ratio of employee compensation to gross value added of the corporate business sector. Both series are from the BEA, NIPA Table 1.14, lines 1 and 4 .

To construct data for $p_{t}$, I start with the nominal market capitalization of the S\&P 500 stock market index from www.siblisresearch.com. The nominal market capitalization is deflated using the output price index noted above and then divided by U.S. population to create a series for real equity value per person.

The University of Michigan consumer sentiment index is from www.sca.isr.umich.edu/tables.html. The Conference Board's consumer confidence index is from www.conference-board.org/data. 


\section{References.}

Akerlof, G. and R. Shiller (2009), Animal Spirits: How Human Psychology Drives the Economy, and Why it Matters for Global Capitalism, Princeton: Princeton University Press.

Ambler, S., and A. Paquet (1994), "Stochastic depreciation and the business cycle," International Economic Review 35, 101-116.

Angeletos, G.-M., F. Collard and H. Dellas (2018), "Quantifying confidence," Econometrica, forthcoming.

Basu, P. (1987), "An adjustment cost model of asset pricing," International Economic Review 28, 609-621.

Benhabib, J., and R.E.A. Farmer (1994), "Indeterminacy and increasing returns," Journal of Economic Theory 63. 19-41.

Benhabib, J., P. Wang, and Y. Wen (2015), "Sentiments and aggregate demand fluctuations," Econometrica 83, 549-585.

Brown G.W. and M.T. Cliff (2004), "Investor sentiment and the near-term stock market," Journal of Empirical Finance 11, 1-27.

Brown G.W. and M.T. Cliff (2005), "Investor sentiment and asset valuation," Journal of Business 78, 405-440.

Cassou, S.P. and K.J. Lansing (1997), "Welfare, Stabilization, or Growth: A Comparison of Different Fiscal Objectives," J. Hairault, P. Hénin, and F. Portier, eds., Business Cycles and Macroeconomic Stability: Should We Rebuild Built-in Stabilizers?, 55-78, Boston: Kluwer Academic Publishers.

Chahrour, R. and K. Jurado (2018), "News or noise? The missing link," American Economic Review 108, 1702-1736.

Chahrour, R. and R. Ulbricht (2017), "Information-driven business cycles: A primal approach," Boston College Working Papers in Economics 925.

Chari, V.V., P.J. Kehoe, and E.R. McGrattan (2007), "Business cycle accounting," Econometrica 75, 781-836.

Christiano, L.J., R. Motto, and M. Rostagno (2014), "Risk shocks," American Economic Review 104, 27-65.

Farmer, R.E.A. (2012), "Confidence, crashes, and animal spirits," Economic Journal 122, $155-172$.

Farmer, R.E.A. (2013), "Animal spirits, financial crises, and persistent unemployment," Economic Journal 123, 317-340.

Farmer, R.E.A. (2015), "The stock market crash really did cause the Great Recession," Oxford Bulletin of Economics and Statistics 77, 617-633.

Farmer, R.E.A., and J.-T. Guo (1994), "Real business cycles and the animal spirits hypothesis," Journal of Economic Theory 63, 42-72.

Farmer, R.E.A., and J.-T. Guo (1995), "The econometrics of indeterminacy: An applied study," Carnegie Rochester Conference Series on Public Policy 43, 225-272.

Fisher, K.L. and M. Statman (2003), "Consumer confidence and stock returns," Journal of Portfolio Management 30(1), 115-127.

Frydman, R. and J.R. Stillwagon (2018), "Fundamental factors and extrapolation in stockmarket expectations: The central role of structural change," Journal of Economic Behavior and Organization 148, 189-198. 
Furlanetto, F. and M. Seneca (2014), "New perspectives on depreciation shocks as a source of business cycle fluctuations," Macroeconomic Dynamics 18, 1209-1233.

Gelain, P., K.J. Lansing, and G.J. Natvik (2018), "Explaining the boom-bust cycle in the U.S. housing market: A reverse-engineering approach," Journal of Money Credit and Banking, forthcoming.

Greenwald, D.L., M. Lettau and S.C. Ludvigson (2014), "The origins of stock market fluctuations," NBER Working Paper No. 19818.

Greenwood, J., Z. Hercowitz, and G.W. Huffman (1988), "Investment, capacity utilization, and the real business cycle," American Economic Review 78, 402-417.

Greenwood, R. and A. Shleifer (2014), "Expectations of returns and expected returns," Review of Financial Studies 27, 714-746.

Guo, J.-T. and K.J. Lansing (2007), "Maintenance expenditures and indeterminacy under increasing returns to scale," International Journal of Economic Theory 3, 147-158.

Hall, R.E. (1997), "Macroeconomic fluctuations and the allocation of time," Journal of Labor Economics 15(1), S223-S250.

Hansen, G.D. (1985), "Indivisible labor and the business cycle," Journal of Monetary Economics $16,309-327$.

Jermann, U.J. (1998), "Asset pricing in production economies," Journal of Monetary Economics 41, 257-275.

Justiniano, A., G.E. Primiceri, and A. Tambalotti (2010), "Investment shocks and business cycles," Journal of Monetary Economics 57, 132-145.

Kaplan, G. and S. Schulhofer-Wohl (2018), "The changing (dis-)utility of work," NBER Working Paper No. 24738.

Keynes, J. M. (1936), General Theory of Employment, Interest and Money, London: Macmillian.

Lansing, K.J. (2006), "Lock-in of extrapolative expectations in an asset pricing model," Macroeconomic Dynamics 10, 317-348.

Lansing, K.J. (2010), "Rational and near-rational bubbles without drift," Economic Journal $120,1149-1174$.

Lansing, K.J. (2012), "Speculative growth, overreaction, and the welfare cost of technologydriven bubbles," Journal of Economic Behavior and Organization 83, 461-483.

Lansing, K.J. (2015), "Asset pricing with concentrated ownership of capital and distribution shocks," American Economic Journal-Macroeconomics 7, 67-103.

Lansing, K.J. (2016), "On variance bounds for asset price changes," Journal of Financial Markets 28, 132-148

Lansing, K.J. (2017), "Stock market valuation and the macroeconomy," Federal Reserve Bank of San Francisco Economic Letter 2017-336, November 13.

Lansing, K.J. and S.F. LeRoy (2014), "Risk aversion, investor information, and stock market volatility," European Economic Review 70, 88-107.

Lansing, K.J. and A. Markiewicz (2018), "Top incomes, rising inequality, and welfare," Economic Journal 128, 262-297.

Lansing, K.J., S.F. LeRoy, and J. Ma (2018), "Examining the sources of excess return predictability: Stochastic volatility or market inefficiency?" Federal Reserve Bank of San Francisco, Working Paper. 
Lefévre, E. (1923), Reminiscences of a Stock Operator, New York: John Wiley (originally published by G.H. Doran).

LeRoy, S.F. and R.D. Porter (1981), "The present-value relation: Tests based on implied variance bounds," Econometrica 49, 555-577.

Liu, Z., D.F. Waggoner and T. Zha (2011), "Sources of macroeconomic fluctuations: A regimeswitching DSGE approach," Quantitative Economics 2, 251-301.

Milani, F. (2010), "Expectation shocks and learning as drivers of the business cycle," Economic Journal 121, 379-401.

Milani, F. (2017), "Sentiment and the U.S. business cycle," Journal of Economic Dynamics and Control 82, 289-311.

Pigou, A.C. (1927), Industrial Fluctuations, London: Macmillan.

Ríos-Rull, J.V. and R. Santaeulàlia-Llopis (2010), "Redistribution shocks and productivity shocks," Journal of Monetary Economics 57, 931-948.

Rogerson, R. (1988), "Indivisible labor, lotteries, and equilibrium," Journal of Monetary Economics 2, 3-16.

Schmeling, M. (2009), "Investor sentiment and stock returns: Some international evidence," Journal of Empirical Finance 16, 394-408.

Shiller, R.J. (1981), "Do stock prices move too much to be justified by subsequent changes in dividends?," American Economic Review 71, 421-436.

Smets, F. and R. Wouters (2007), "Shocks and frictions in US business cycles: A Bayesian DSGE approach," American Economic Review 97, 586-606.

Wen, Y. (1998), "Capacity utilization under increasing returns to scale," Journal of Economic Theory 81, 7-36.

Young, A.T. (2004), "Labor's share fluctuations, biased technical change, and the business cycle," Review of Economic Dynamics 7, 916-931. 
Figure 1: U.S. Macroeconomic Variables
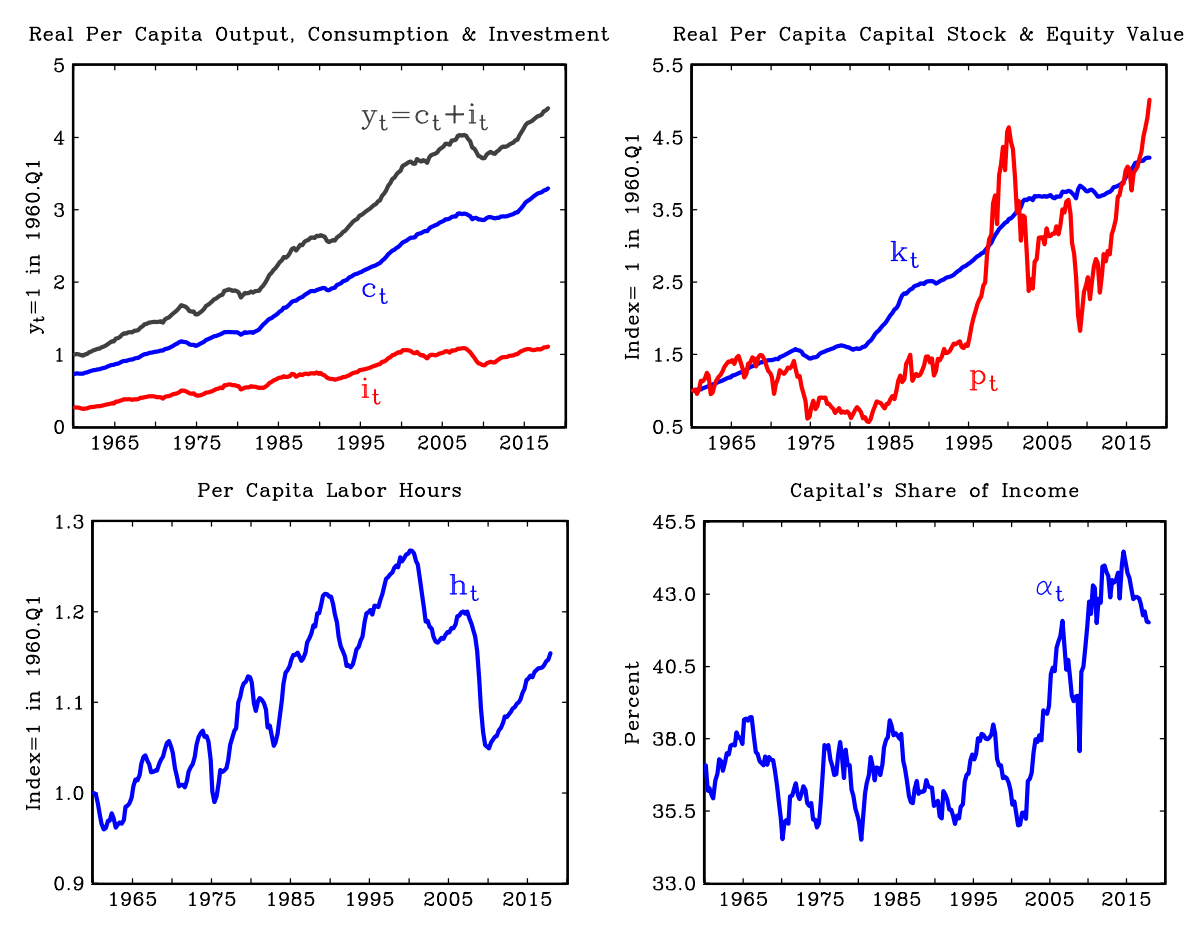

The baseline simulation exactly replicates the observed U.S. time paths of the variables $y_{t}, c_{t}, i_{t}, h_{t}, k_{t}, p_{t}$, and $\alpha_{t}$ from 1960.Q1 to 2017.Q4. Data series are constructed as described in Appendix B. 
Figure 2: U.S. Macroeconomic Ratios
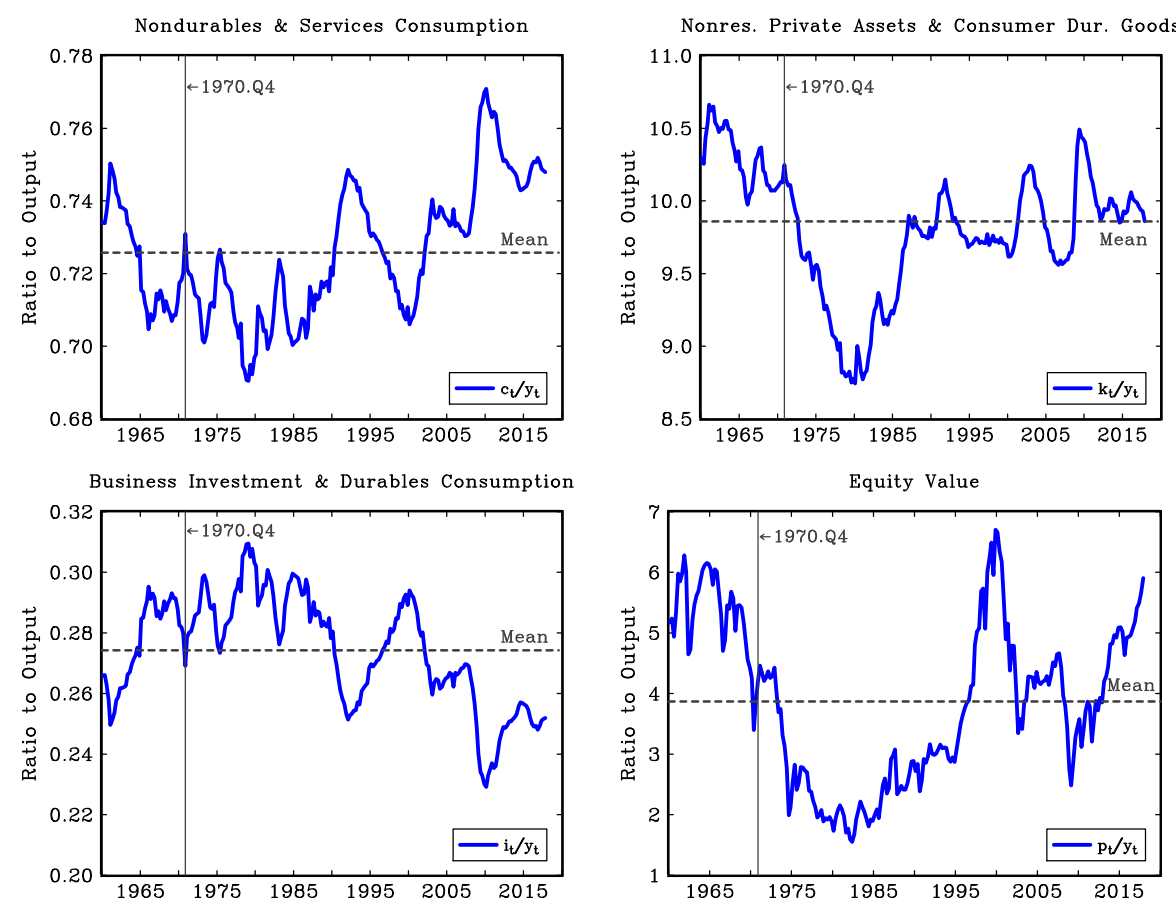

The ratios of U.S. macroeconomic variables to output are close to their long-run means in 1970.Q4. Parameter values are chosen so that the steady-state, trend, or ergodic mean values of model variables correspond to the values observed in the data in 1970.Q4. 
Figure 3: Model-Identified Shocks
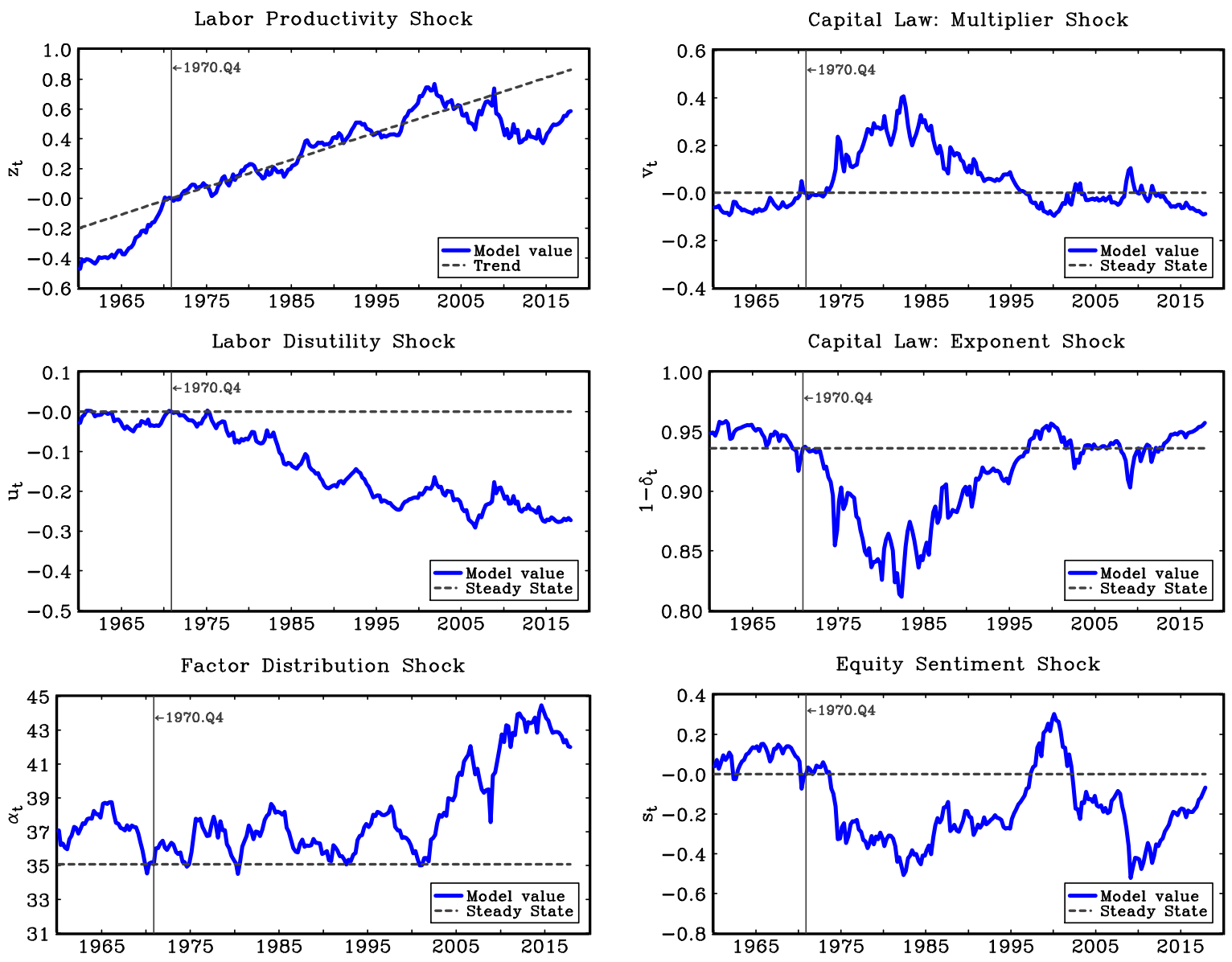

The panels show the time series of stochastic shocks that are needed for the model to exactly replicate the time paths of the seven U.S. macroeconomic variables shown earlier in Figure 1. By construction, all shocks are equal to their trend or steady state values in 1970.Q4. The equity sentiment shock reaches its maximum value in 2000.Q1, coinciding with the peak of the NASDAQ technology stock bubble. 
Output and Consumption
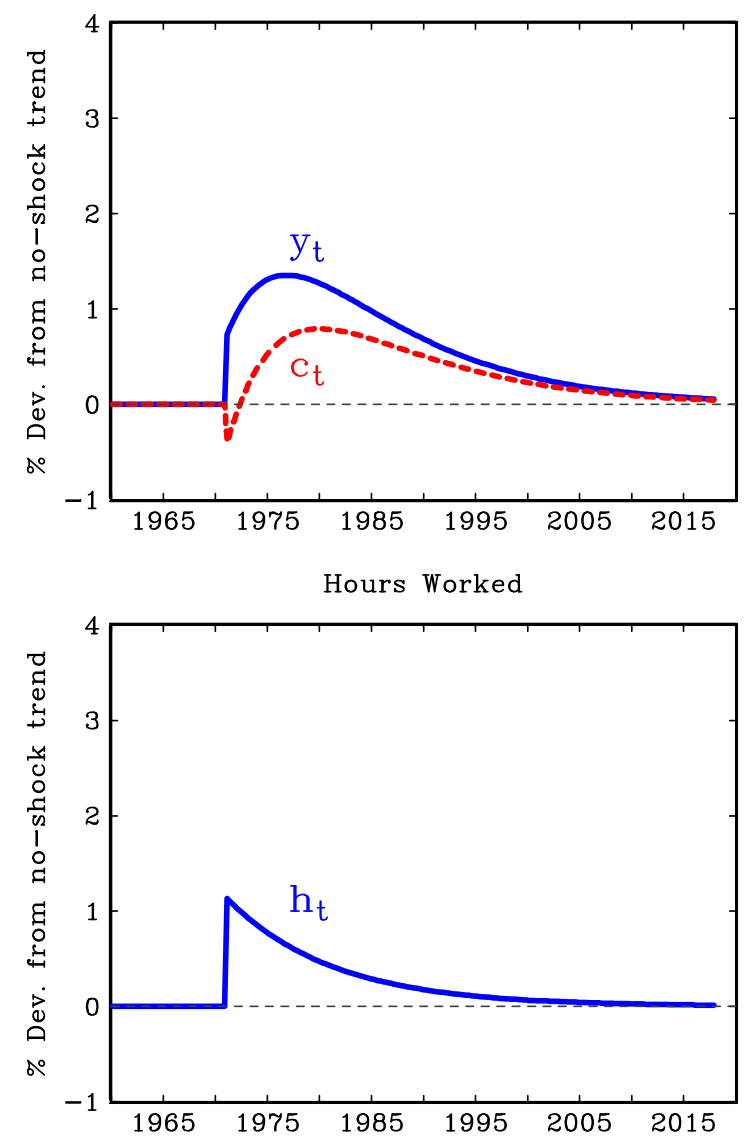

Investment and Capital Stock
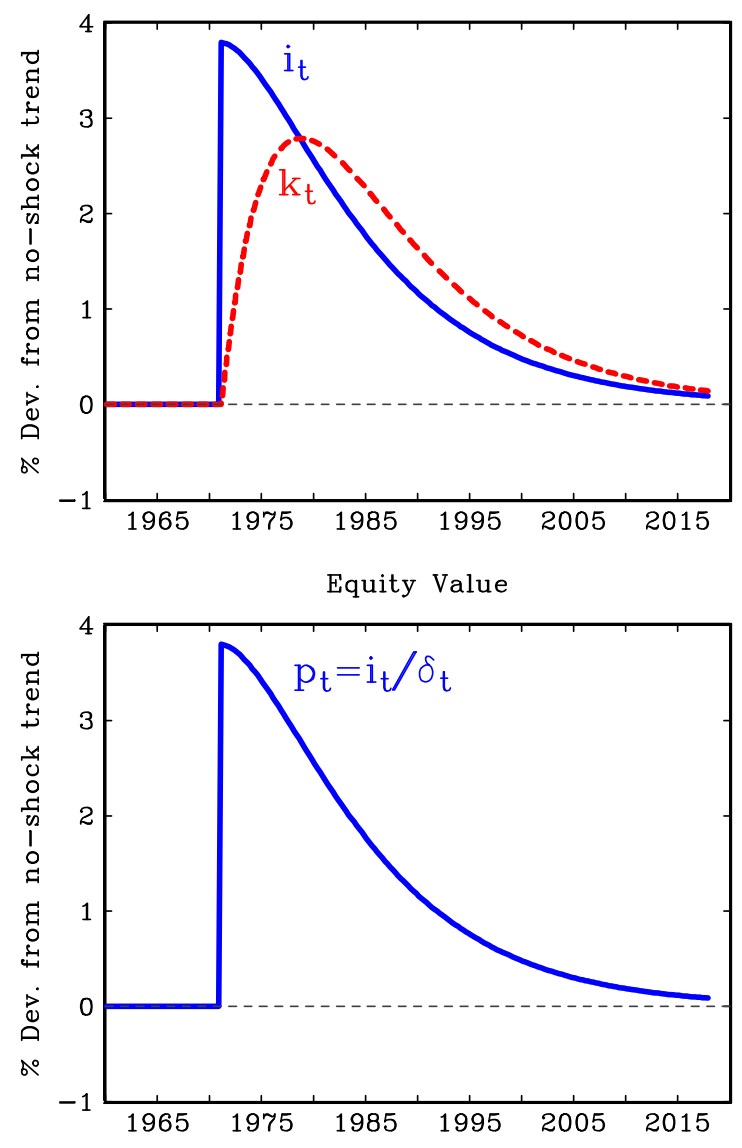

Figure 4: Impulse Responses to Model Equity Sentiment Shock

Notes: Movements in the equity sentiment shock capture the notion of animal spirits-driven fluctuations. The panels show the percent deviation of each variable from its no-shock trend. A positive innovation to the equity sentiment shock leads to an immediate increase in output, hours worked, investment, and equity value. But since the capital stock cannot respond immediately, the initial increase in output is not sufficient to allow both consumption and investment to increase on impact. Consumption drops slightly on impact, but then increases with the other variables as the capital stock starts increasing in response to higher investment. Since $\delta_{t}$ is constant here, movements in equity value $\left(p_{t}=i_{t} / \delta_{t}\right)$ exactly mimic the movements in investment. 
Figure 5: Measures of Sentiment: Model versus U.S. Data

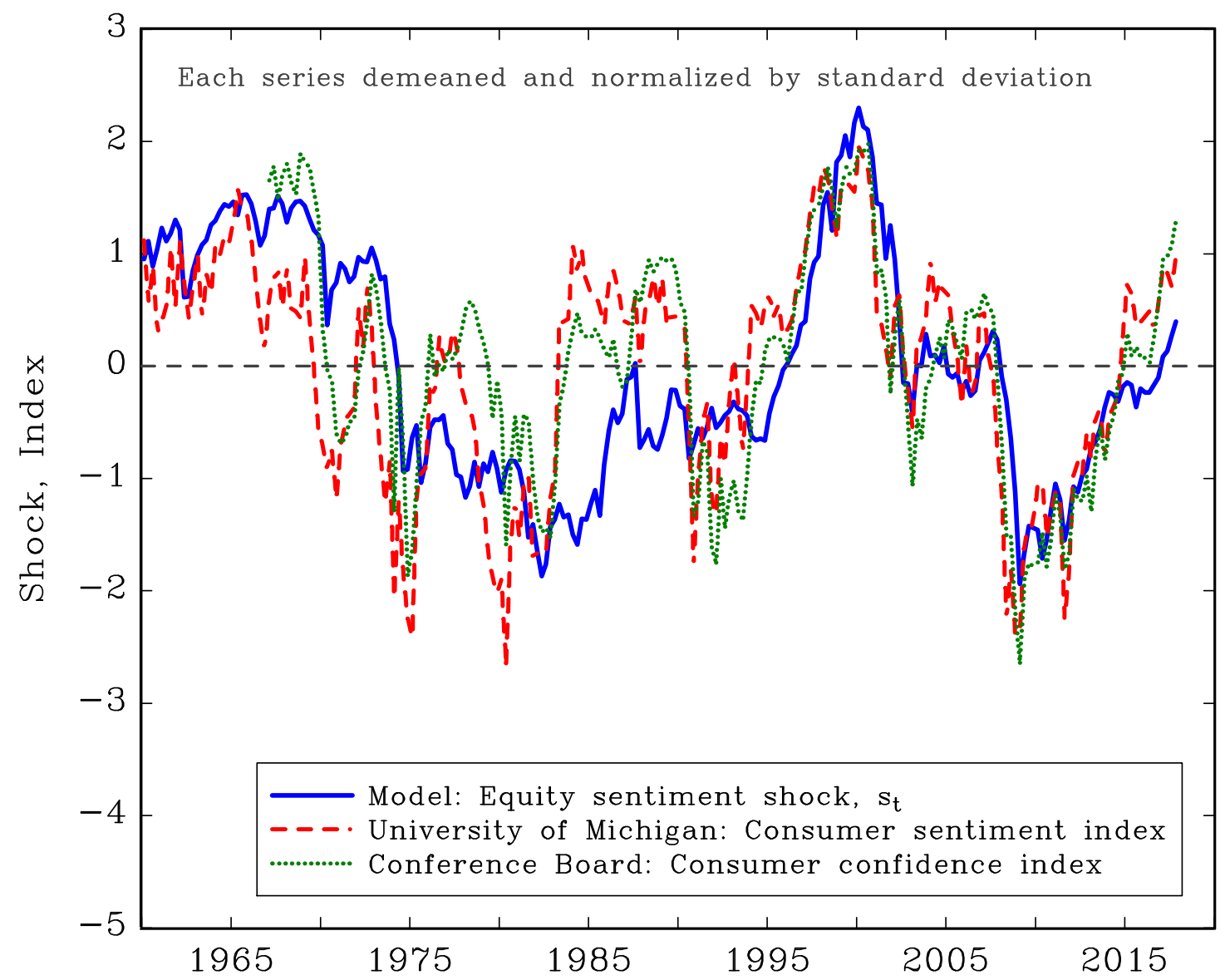

The model-identified equity sentiment shock is strongly correlated with survey-based measures of U.S. consumer sentiment. The correlation coefficient between $s_{t}$ and the University of Michigan index is 0.63. The correlation coefficient between $s_{t}$ and the Conference Board index is 0.71 . The figure confirms that it is appropriate to view the model-identified series for $s_{t}$ as capturing a measure of sentiment. 
Figure 6: Counterfactual Scenarios
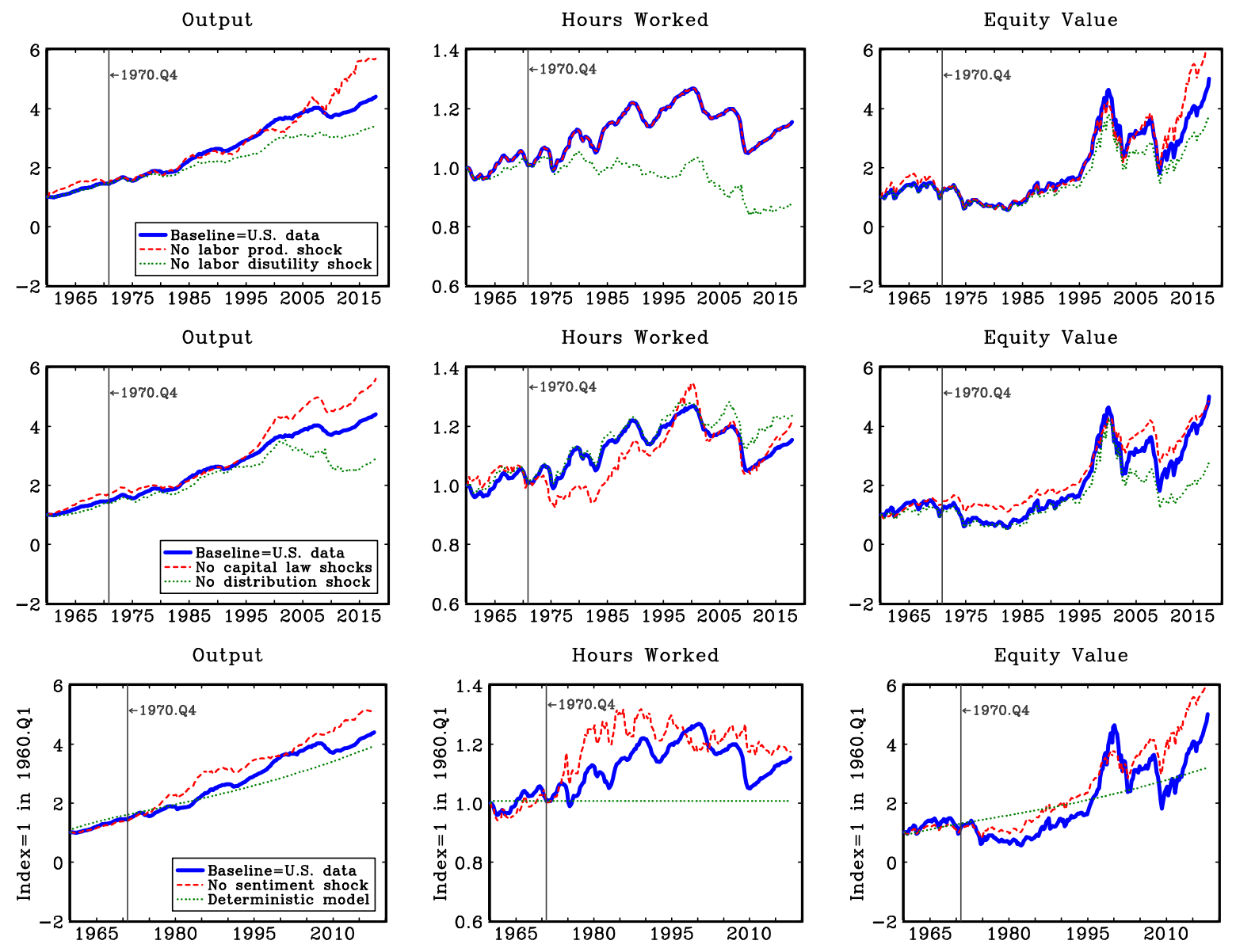

The panels show the effects of shutting off one or more of the various shocks on output (left panels), hours worked (middle panels), and equity value (right panels). A large gap between the model counterfactual path and the U.S. data path (blue line) implies that the omitted shock(s) play an important role in allowing the model variable to match the path of the corresponding U.S. variable. 